\title{
Estimativa de área cultivada com arroz irrigado para o estado do rio grande do sul a partir de imagens Modis
}

\author{
Estimative of the cultivated area with irrigated rice for the State of Rio Grande do Sul by \\ Modis images
}

\author{
1,2,3,5 Universidade Federal do Rio Grande do Sul - UFRGS - Brasil \\ ${ }^{4}$ Universidade Estadual de Campinas - UNICAMP - Brasil
}

Eliana Veleda Klering ${ }^{1}$, Denise Cybis Fontana ${ }^{2}$, Rita Alves ${ }^{3}$, Jansle Rocha ${ }^{4}$, Moacir Antonio Berlato ${ }^{5}$

\begin{abstract}
Resumo
Este trabalho teve como objetivo testar uma metodologia de baixo custo e fácil implantação, utilizando imagens MODIS, para definir as áreas cultivadas com arroz irrigado no Rio Grande do Sul (RS) e monitorar o cultivo ao longo do ciclo para dez safras agrícolas. O estudo foi realizado abrangendo as seis regiões orizícolas do Estado do RS. Foram utilizados dados oficiais de área cultivada com arroz irrigado e imagens NormalizedDifferenceVegetation Index/ ModerateResolutionImagingSpectroradiometer (NDVI/MODIS) referentes às safras agrícolas de 2000/01 até 2009/10. A metodologia testada baseou-se no comportamento espectro-temporal da cultura do arroz irrigado. As maiores diferenças entre os valores de área estimados e os oficiais, em nível regional, foram de -11,5\% na Planície Interna e 5\% na Depressão Central. Os menores desvios ocorreram nas regiões da Campanha e Fronteira Oeste, sendo respectivamente de 2,2\% e-3,1\%. Os resultados mostram que a metodologia proposta é eficiente e pode ser usada tanto para complementar o atual sistema nacional de previsão de safras, como para o monitoramento das áreas cultivadas no RS.
\end{abstract}

Palavras-chave: previsão de safras, NDVI, Oryza sativa.

\begin{abstract}
The objective of this research was to test a methodology of low cost making and easy implementation, using MODIS images for defining the irrigate rice areas in Rio Grande do Sul (RS), State, aiming crop cycle monitoring for the ten crop years. The study was performed involving six rice production regions of RS, State. It was used the official data of area cultivated with rice and Normalized Difference Vegetation Index/Moderate Resolution Imaging Spectroradiometer (NDVI/MODIS) images, to the crop years from 2000/01 to 2009/10. The methodology used was based on the spectral-temporal behavior of the rice culture. The biggest differences between the estimated values of the cultivated area and the official records at the regional level were $-11.5 \%$ in the PlanicieInterna and $5 \%$ in the Depressão Central. The minor deviations occurred in the regions of the FronteiraOeste andCampanha, being respectively $2.2 \%$ and $-3.1 \%$. The results showed that the proposed method is efficient and can be used to both complement the current national system of harvests forecasting, and for the monitoring of the cultivated areas in RS, State.
\end{abstract}

Keywords: harvests forecasting, NDVI, Oryza sativa. 


\section{Introdução}

O Estado do Rio Grande do Sul (RS) é um dos maiores produtores e exportadores de grãos do Brasil, tendo sido responsável, na safra 2012/13, por $67,5 \%$ da produção brasileira de arroz (cerca de 8,1 milhões de toneladas), com área plantada deste cereal superior a 1,04 milhão de hectares (IBGE, 2013). Estima-se que, anualmente, essa produção corresponda a um valor bruto de cinco bilhões de reais, representando $3 \%$ da arrecadação do Imposto de Circulação de Mercadorias e Serviços(ICMS) e 2,27\% do Produto Interno Bruto (PIB)do Estado (IRGA, 2013).

A geração de estimativas de área cultivada, produção e rendimento de grãos de arroz irrigado no Brasil é realizada pelo Instituto Brasileiro de Geografia e Estatística (IBGE). Nesses levantamentos, baseados em protocolos internacionalmente aceitos, são considerados dados obtidos através de entrevistas com produtores, dados de cooperativas e informações de financiamentos agrícolas (IBGE, 2002). Assim, a obtenção destas informações é extremamente trabalhosa e onerosa e os dados coletados, de certa forma, são subjetivos (LIU, 2006). Além disso, a metodologia não permite uma análise quantitativa de eventuais erros ocorridos ou localização espacial das lavouras (RIZZI; RUDORFF, 2005). Nesse contexto, torna-se importante a proposição de métodos objetivos e de fácil implantação que possam ser incorporados a metodologia oficial. A adoção destes métodos pode contribuir parao aperfeiçoamento das estimativas, gerando informações que serão empregadas, por exemplo, na definição de políticas públicas e na formação de preços (ASSAD et al., 2007).

Devido às características de moderada resolução espacial e alta resolução temporal, inúmeros trabalhos tem utilizado os índices de vegetação (IVs) provenientes do sensor Moderate Resolution Imaging Spectroradiometer (MODIS), para determinar as máscaras de cultivo para a cultura do arroz irrigado, ou seja, para estimar as áreas ocupadas com a cultura (XIAO et al., 2005; XIAO et al., 2006;D' ARCO et al., 2007; BOSCHETTI et al., 2009).

Entre os IVs mais utilizados em estudos que abrangem cultivos agrícolas destacam-se o NDVI (Índice de Vegetação por Diferença Normalizada do inglês Normalized Difference Vegetation Index) e o EVI (Índice de Vegetação Realçado do inglês Enhanced Vegetation Index). Os IVs resultam de combinações de valores de reflectância em dois ou mais intervalos de comprimento de onda, sendo em geral utilizadas bandas que abrangem o vermelho e o infravermelho. Estes índices servem como indicadores do crescimento, do vigor da vegetação verde e podem ser utilizados para determinar alguns parâmetros biofísicos, tais como Índice de Área Foliar (IAF), biomassa, atividade fotossintética, podendo mostrar uma boa relação com o rendimento da cultura (D’arco, 2007; Ponzoni, 2001).

Dentro deste contexto, D'arco et al. (2007) determinaram as áreas cultivadas com arroz irrigado no RS e mostraram que as melhores estimativas foram obtidas utilizando-se classificação digital nãosupervisionada Isoseg de imagens NDVI/MODIS do período de máximo desenvolvimento vegetativo da cultura. Entretanto, inúmeros trabalhos têm explorado o atributo espectro-temporal de IVs do sensor MODIS para estimar a área cultivada com arroz irrigado (THIRUVENGADACHARI; SAKTHIVADIVEL, 1997; SAKAMOTO et al.,2005; MOTOHKA et al., 2009), ou seja, as variações dos IVs ao longo do ciclo. Utilizando este atributo, Klering (2007) determinou as áreas cultivadas com arroz irrigado para o RS utilizando imagens de NDVI/MODIS, dos períodos de mínimo e máximo desenvolvimento vegetativo, para o estabelecimento das máscaras de cultivo. Os resultados mostraram que as áreas estimadas foram, em média, $25 \%$ superiores aos dados oficiais de área cultivada. Os resultados obtidos nestes estudos, apesar de bastante razoáveis, apontaram lacunas de entendimento das causas de variação entre dados oficiais e estimados.

Considerando a importância econômica da cultura do arroz para o Estado, as possibilidades de utilização das imagens orbitais em programas de previsão de safras e as lacunas de conhecimento, este trabalho teve como objetivo testar uma metodologia, utilizando imagens de NDVI provenientes do sensor orbital MODIS, para construção de uma máscara de cultura para o arroz irrigado no RS. A metodologia busca definir as áreas para fins de monitoramento das condições de crescimento e desenvolvimento da cultura, apresentando características de objetividade, baixo custo e fácil implantação, visando o uso em programas operacionais de acompanhamento e previsão de safras.

\section{Material e Métodos}

O estudo foi realizado sobre a região produtora de arroz irrigado do RS, situada na metade sul do Estado e que, segundo divisão político-administrativa do Instituto Rio Grandense do Arroz (IRGA), é subdividida em regiões denominadas: Fronteira Oeste, Campanha, Depressão Central, Planície Costeira Interna à Lagoa dos Patos, Planície Costeira Externa à Lagoa dos Patos e Zona Sul (Figura 1).

O período de estudo abrangeu 10 safras agrícolas, de 2000/01 até 2009/10, estendendo-se de setembro a abril, compreendendo, assim, o período de desenvolvimento da cultura do arroz irrigado no RS. 


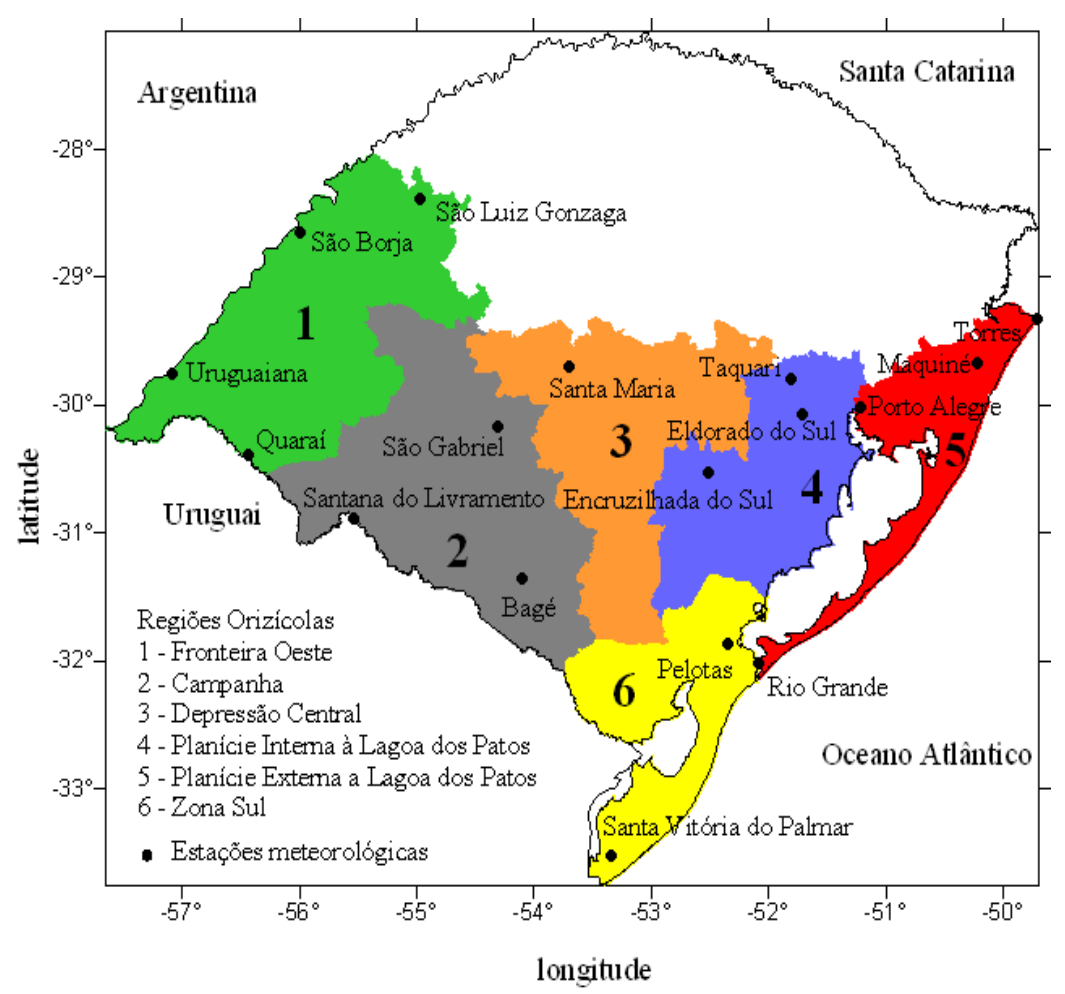

Figura 1. Regiões orizícolas do Estado RS e estações meteorológicas utilizadas. Fonte de dados: IRGA e $8^{\circ}$ DISME/INMET.

Foram utilizados dados oficiais de área cultivada, produção e rendimento de grãos de arroz irrigado obtidos a partir do Levantamento Sistemático da Produção Agrícola (LSPA) do IBGE.

Utilizaram-se, também, 280 imagens de NDVI provenientes do sensor MODIS, a bordo da plataforma orbital Terra, referentes ao produto MOD13Q1 da coleção 5. Para cobrir a área de estudo são necessárias duas cenas correspondentes aos tiles h13v11 e h13v12 (MODIS, 2003). Este produto foi obtido de forma gratuita, mediante cadastro antecipado, através do site do Sistema de Observação da Terra (EOS) da National Aeronautics and Space Administration (NASA). ${ }^{1}$

Após o download das imagens correspondentes às cenas de interesse e ao período de estudo, estas passaram pelo processo de mosaicagem. A partir destes, foram recortadas as áreas de interesse. Posteriormente, as imagens tiveram sua projeção alterada do formato original (sinusoidal) para a projeção Cônica Equivalente de Albers, devido ao interesse em quantificar área. Os parâmetros utilizados na referida projeção foram: Datum SAD69/Brasil com longitude do meridiano central de $-54^{\circ}$ e latitudes dos paralelos padrões de $-33^{\circ} \mathrm{e}-27^{\circ}$. Todas as etapas deste trabalho que envolveram processamento de imagens foram executadas utilizando-se o software Envi 4.5.

Para a construção das máscaras de cultivo de arroz irrigado, utilizou-se uma metodologia baseada

1 Disponível em https://wist.echo.nasa.gov/ wist/api/imswelcome/. no mapeamento de culturas de verão proposto por Araújoetal. (2011). Neste método, as máscaras de cultura são construídas através da classificação digital supervisionada. As amostras para treinamento do classificador são coletadas em uma imagem de composição colorida, frequentemente denominada composição RGB ( $R=$ =vermelho, $G=$ =verde, $B=$ azul),elaborada a partir de imagens multitemporais NDVI/MODIS, de determinados períodos do ciclo da cultura. Estas composições tiveram como objetivo destacar apenas as áreas cultivadas com arroz irrigado.

Segundo o calendário agrícola médio do arroz irrigado no RS, a cultura é implantada na primeira quinzena de outubro, tem a lâmina d'água aplicada na segunda quinzena de novembro e atinge o máximo crescimento vegetativo entre a segunda quinzena de dezembro e a primeira de janeiro (Figura 2). Assim, na elaboração da imagem composição colorida, a imagem correspondente ao menor crescimento vegetativo (período de entrada de água na lavoura:- primeira quinzena de novembro - primeira imagem de mínimo) foi alocada no canal verde. No canal azul foi colocada a imagem correspondente ao período de implementação da cultura (primeira quinzena de outubro - segunda imagem de mínimo) e no canal vermelho foi colocada a imagem correspondente ao período de maior crescimento vegetativo (primeira quinzena de janeiro - imagem de máximo). De forma a contemplar as diferenças de manejo entre regiões e diferentes anos agrícolas, foram geradas três com- 


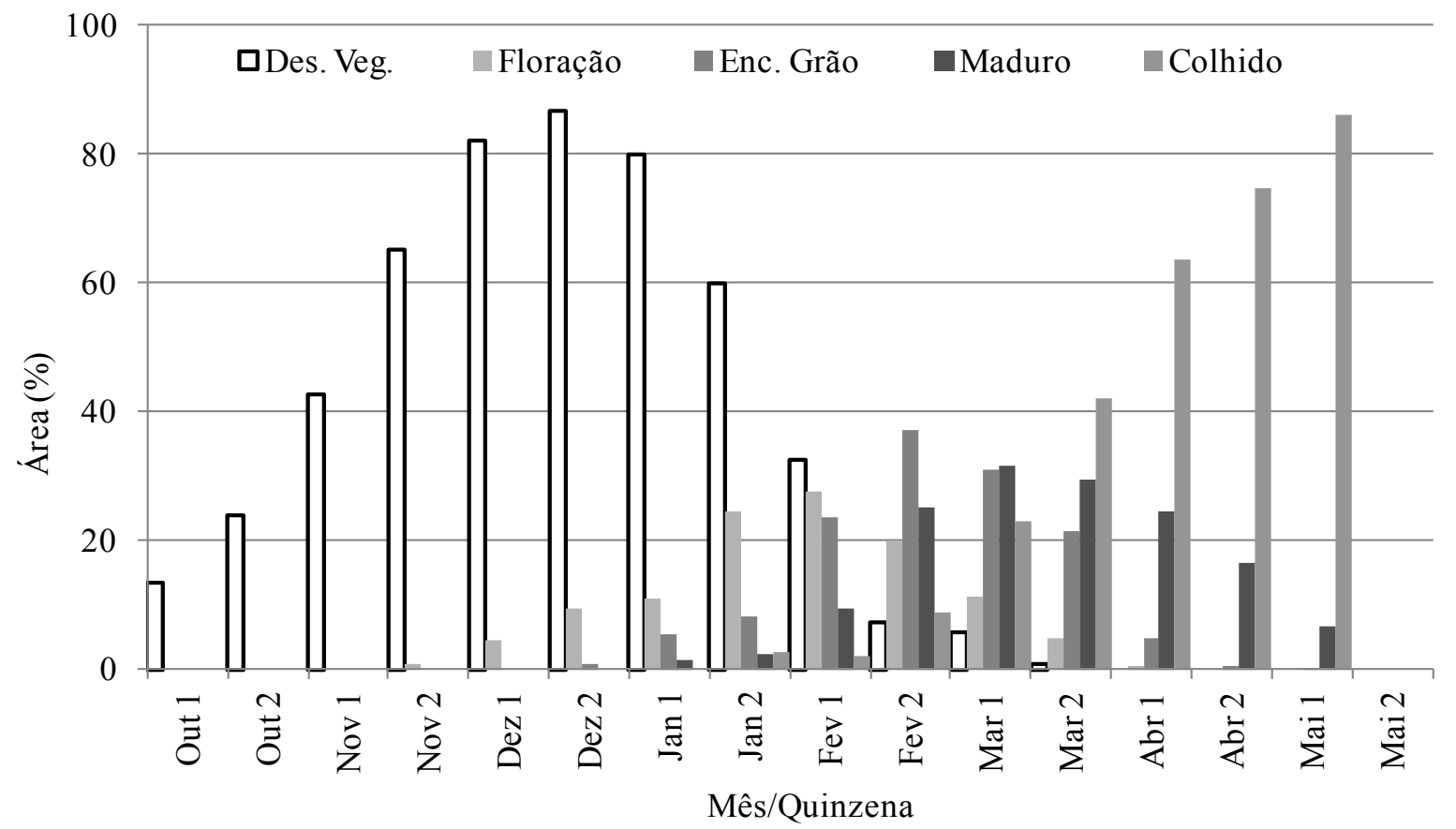

Figura 2. Calendário agrícola médio do arroz irrigado, safras 2000/01 a 2004/05, para o Estado do RS. Fonte dos dados: EMATER/ RS.

posições RGB deslocando-se em um e dois períodos as datas das imagens de máximos e mínimos NDVI.

O método de classificação digital supervisionada Paralelepípedo utiliza uma abordagem de classificação determinística, onde são identificados os valores mínimos e máximos dos histogramas das amostras em cada banda, que são usados para definir os vértices de um paralelepípedo no espaço de atributos. Deste modo, o pixel cujo valor se encontrar dentro desse paralelepípedo será classificado como pertencente à classe de interesse (MOREIRA, 2005). Assim, foram selecionadas amostras em áreas com maior crescimento vegetativo dentro de cada composição RGB, as quais, provavelmente, estão associadas a lavouras de arroz irrigado. A imagem classificada foi gerada tendo somente duas classes, sendo uma denominada "arroz" e a outra, "não arroz". Em seguida, selecionou-se apenas a classe "arroz", que foi convertida em um arquivo vetorial, gerando assim uma máscara de cultura para cada composição RGB.

Para a obtenção da máscara final de cada safra foi feita a sobreposição das máscaras correspondentes às três composições RBG. A operação de sobreposição seguiu a seguinte regra: a primeira abrange a segunda exceto nos casos em que valor do pixel for zero, ou seja, houve um somatório cumulativo das máscaras.
A partir da geração das máscaras de cultivo, foram quantificadas as áreas cultivadas com arroz irrigado em nível regional. Essas áreas foram comparadas com as áreas oficiais, fornecidas pelo IBGE, através da elaboração de um gráfico de dispersão (1:1), do índice de concordância de Willmott (d) e do coeficiente de correlação de Pearson (r).

Foram construídos mapas da distribuição espacial das áreas cultivadas com arroz irrigado para as safras de estudo. A partir da sobreposição dos mapas de todas asdezsafras foi determinada a área potencial de cultivo do arroz irrigado para a região orizícola do Estado do RS.

\section{Resultados e Discussão}

Na Figura 3, é apresentada a comparação entre a estimativa oficial de área de cultivo de arroz e a área determinada a partir das composições em RGB de imagens de NDVI para as seis regiões orizícolas nas dez safras agrícolas analisadas. O índice de concordância de Willmott (d), que mede a dispersão dos dados em relação à reta (1:1), mostrou que a concordância dos valores de área de cultivo estimados em relação aos oficiais foi de $95 \%$. A confiabilidade da metodologia também pode ser verificada pelo coeficiente de correlação de Pearson, o qual foi significativo a 1\% de 
probabilidade, pelo teste $t$-Student, com o valor de 0,90.

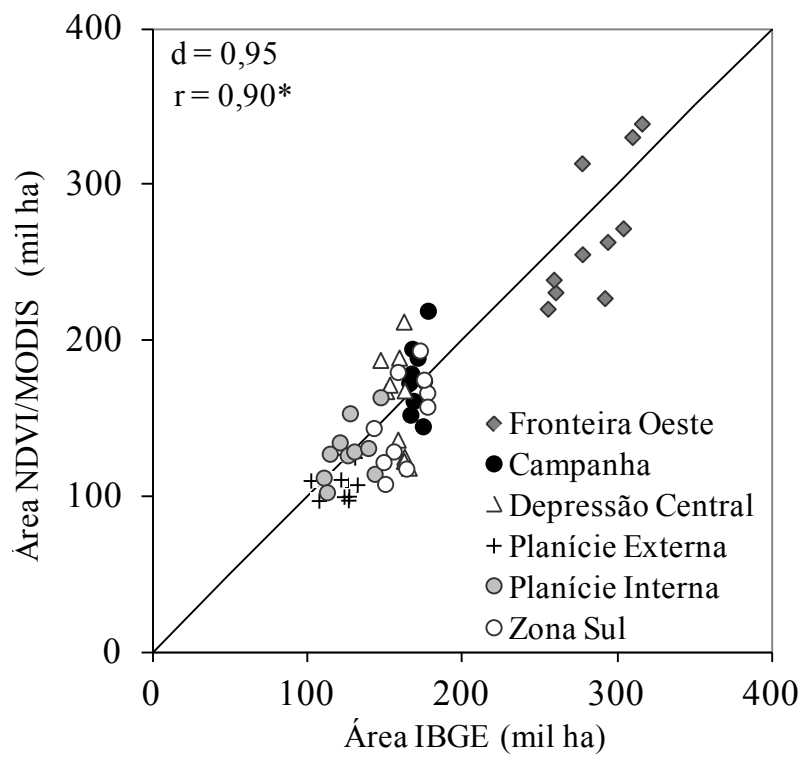

Figura 3. Relação entre a área cultivada com arroz irrigado nas regiões orizícolas do RS, estimada através de composições em RGB de NDVI (Área NDVI/MODIS) e a área oficial fornecida pelo IBGE (Área IBGE). Período: 2000/01 a 2009/10. * Significativo a $1 \%$ de probabilidade pelo teste t-Student.

Na Tabela 1, nota-se que os maiores desvios médios das áreas estimadas através do NDVI em relação às áreas fornecidas pelo IBGE ocorreram nas regiões da Planície Externa (-11,1\%), Depressão Central (5\%), Planície Interna $(-3,5 \%)$ e Zona Sul $(-3,5 \%)$. É possível que estas diferenças estejam relacionadas a aspectos intrínsecos a metodologia utilizada, pois esta, além de reduzir a influência de áreas não agrícolas, também descarta os pixels não puros, ou seja, áreas de bordas de lavouras ou drenagens e nuances de relevo.

Os menores desvios ocorreram nas regiões da Campanha e da Fronteira Oeste, sendo de, respectivamente, $2,2 \%$ e $-3,1 \%$.

Estes resultados são promissores visto que as menores diferenças ocorreram nas regiões de maior área cultivada no Estado, mas diferem dos encontrados por D'arco (2007). Naquele trabalho, o autor mostrou que ocorreram superestimativas em municípios localizados nas regiões com maiores áreas cultivadas (Fronteira Oeste e Campanha) e subestimativas em municípios das regiões com menores áreas cultivadas (Planícies Interna e Externa).

O desvio médio observado quando se considerou o Estado como um todo foi de $-4,5 \%$. Essa tendência de subestimativa das áreas cultivadas com arroz irrigado no RS também foi observada por Weber et al. (2007). É importante ressaltar que as análises oficiais são elaboradas a partir de aspectos regionais, onde são incluídas características distintas de solo, manejo e tratos culturais, de tamanho das lavouras, ou mesmo de diferenças entre as equipes responsáveis pelo levantamento estatístico do arroz, e isto pode ter influência nos resultados oficiais (IBGE) das estimativas da área plantada. Convém salientar, ainda, que a resolução espacial das imagens NDVI/MODIS é de 250 metros, ou seja, a área mínima identificada pelo sensor é de 6,25 ha. Entretanto, este não se constitui com um fator limitante, pois segundo dados do IRGA, apenas 3,4\% das lavouras de arroz irrigado do RS apresentam

Tabela1. Área média cultivada com arroz irrigado no RS estimada através de imagens NDVI/MODIS, dados oficiais (IBGE) e desvios médios (\%). Período 2000/01 a 2009/10.

\begin{tabular}{|c|c|c|c|}
\hline \multirow{2}{*}{ Região } & \multicolumn{3}{|c|}{ Área de cultivo (mil ha) } \\
\hline & MODIS & IBGE & Desvios (\%) \\
\hline Fronteira Oeste & 269,2 & 277,6 & $-3,1$ \\
\hline Campanha & 169,4 & 165,8 & 2,2 \\
\hline Depressão Central & 159,8 & 152,1 & 5,1 \\
\hline Planície Interna & 149,2 & 154,6 & $-3,5$ \\
\hline Planície Externa & 108,6 & 122,2 & $-11,1$ \\
\hline Zona Sul & 149,2 & 159,6 & $-3,5$ \\
\hline RS & 1005,5 & 1052,2 & $-4,5$ \\
\hline
\end{tabular}



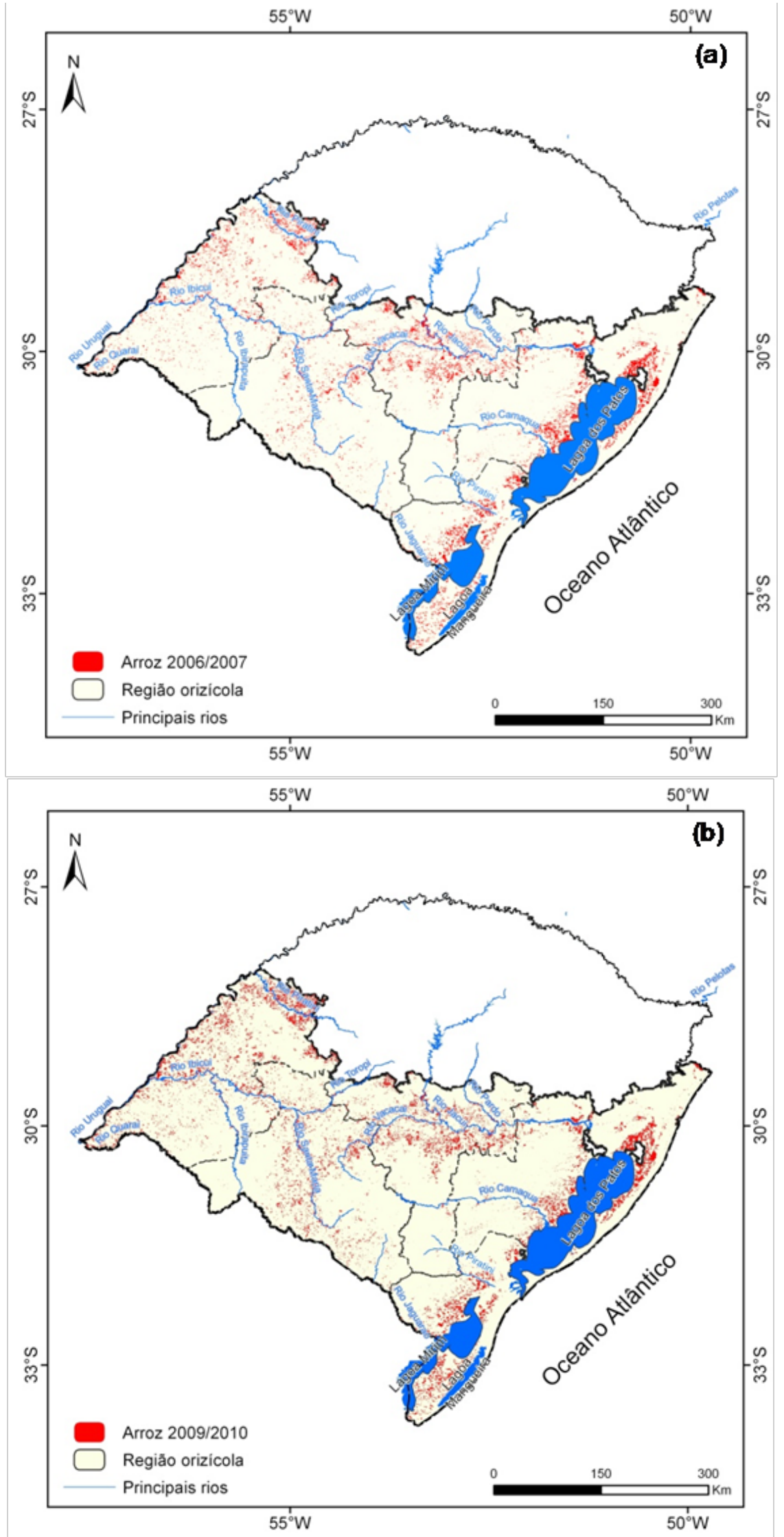

Figura 4. Distribuição espacial da área cultivada com arroz irrigado, estimada através de imagens MODIS, na região orizícola do RS durante as safras de (a) 2006/07 e (b) 2009/10. 
tamanho inferior a 25 ha, sendo o tamanho médio de lavoura de 144,7 ha(IRGA, 2006; SOSBAI, 2010).

Na Figura 4, são apresentadas as distribuições espaciais das áreas cultivadas com arroz irrigado, estimadas a partir das imagens NDVI/ MODIS, para as safras de 2006/07 e de 2009/10. Estas safras foram tomadas como exemplo visto que apresentaram, no período de análise, as maiores e menores áreas cultivadas, respectivamente. Na safra de 2006/07, a área cultivada com arroz irrigado estimada através das imagens NDVI/MODIS foi de 900.232 há, enquanto a área oficial foi de 936.540 ha (subestimativa de 36.308 ha). Já na safra de 2009/10, observou-se uma superestimativa de 29.416 há, sendo a área estimada de 1.118.144 ha e a área oficial de 1.088.728 ha. Apesar das diferenças, verificouse consistência quanto à distribuição espacial em ambas as safras avaliadas.

A máscara de cultivo indicou que, devido à característica da cultura de ser conduzida sob irrigação, as lavouras estão distribuídas próximas a corpos d'água. Nas regiões Planícies Interna, Externa e Zona Sul, destacam-se as áreas cultivadas próximas as Lagoas dos Patos, Mirim e Mangueira. Na Fronteira Oeste, há predomínio das lavouras nas regiões circundantes aos Rios Uruguai, Piratini e Ibicuí. Também destacam-se áreas cultivadas próximas aos Rios Jacuí, Vacacaí e Camaquã na região orizícola Depressão Central. Já na Campanha, não se percebeu um padrão claro de distribuição das lavouras em torno dos principais rios da região, o que pode ser atribuído ao fato de que, aproximadamente, $77 \%$ da água utilizada para irrigação nesta região é proveniente de açudes e barragens (IRGA, 2006).
Quanto à distribuição espacial observa-se, também, que as lavouras apresentam localização variável a cada safra, o que pode ser justificado pela adoção do sistema de pousio e rotação de culturas que é, em média, de dois anos (REIS; SAIBRO, 2004).

De maneira geral, culturas agrícolas apresentam comportamentos espectrais distintos, devido às diferentes interações com a radiação eletromagnética. Isto ocorre devido às diferenças entre as arquiteturas dos dosséis, bem como as distintas densidades de semeadura e espaçamentos entre linhas (SANCHES et. al, 2005). No caso específico do arroz irrigado, onde parte do ciclo de cultivo está sob inundação, com contribuição da resposta espectral da água neste período, é possível, teoricamente, que a cultura seja espectralmente distinguida das demais (XIAO et al., 2002). No entanto, devido à espessura e ao conteúdo de matéria orgânica na lâmina d'água, outras áreas com cultivos de primavera-verão de ciclo semelhante, podem ser incluídas no mapeamento ( $\mathrm{D}^{\prime} \mathrm{ARCO}$ et al., 2007).

Neste trabalho, é provável que os maiores erros, quanto à distribuição espacial estejam relacionados à soja e tenham ocorrido nas regiões da Fronteira Oeste, Campanha e Depressão Central, pois essa cultura apresentou área semeada média semelhante a do arroz durante o período de estudo (Figura 5). Nas demais regiões, é possível que os erros tenham sido menores, pois a área cultivada com soja é bem inferior à cultivada com arroz. Os erros relacionados à cultura do milho provavelmente são os de menor magnitude, já que a área cultivada desse cereal dentro da região é bem menor quando comparada as cultivadas com soja e arroz.

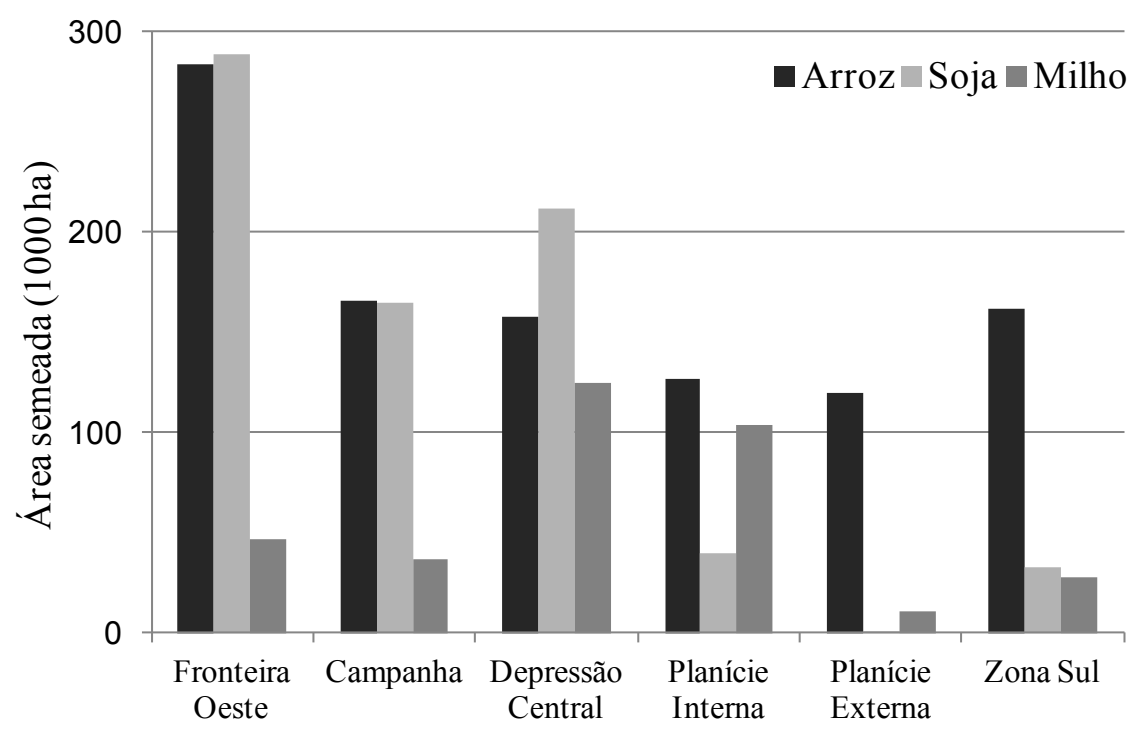

Figura 5. Área semeada média de arroz, soja e milho nas regiões orizícolas do RS. Período: safras agrícolas de 2000/01 até 2009/10. Fonte dos dados: IBGE/LSPA (2012). 


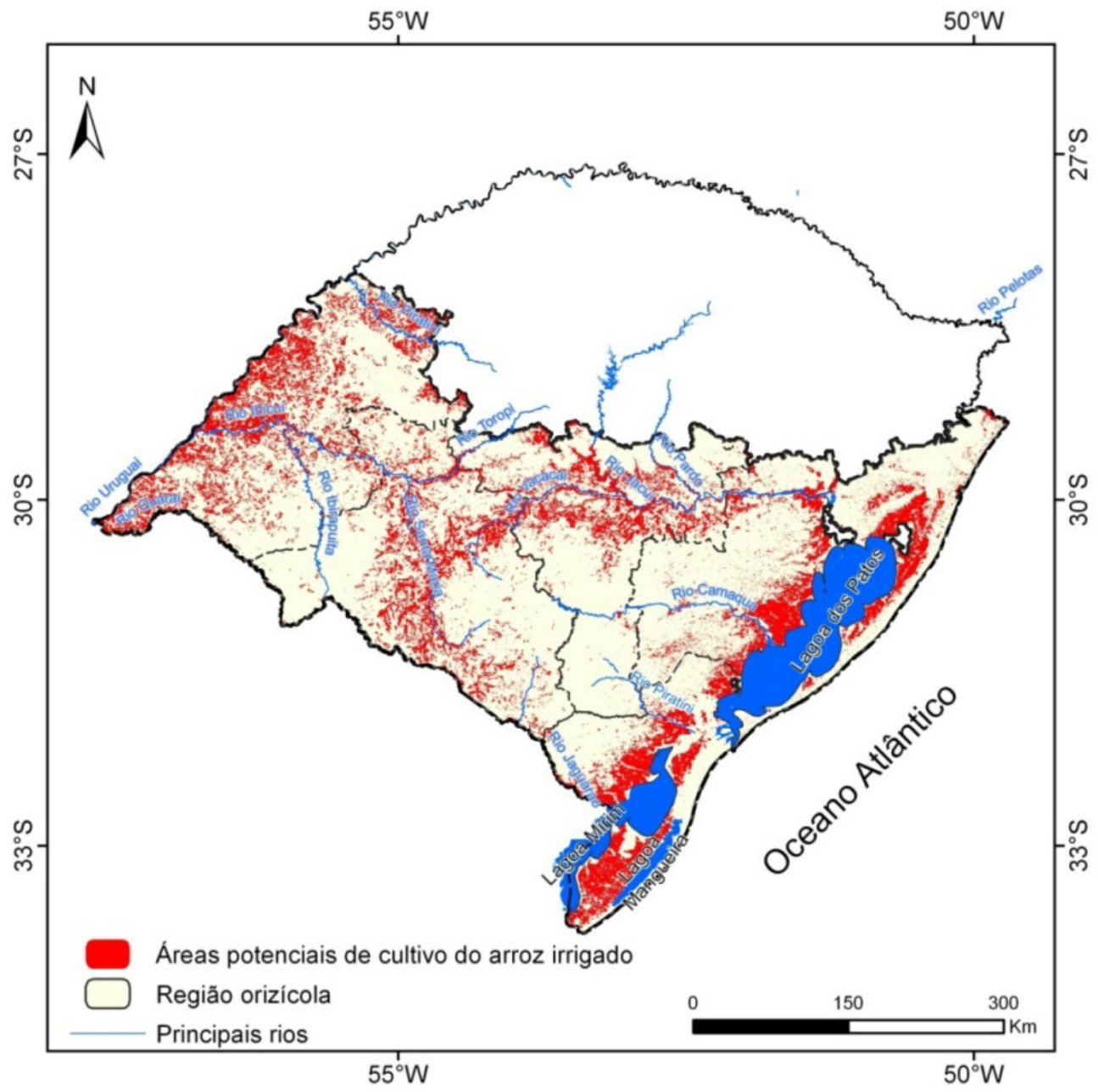

Figura 6. Áreas potenciais de cultivo do arroz irrigado na região orizícola do RS.

Portanto, mais do que a determinação exata das áreas de cultivo de arroz, esta metodologia, que apresenta características de baixo custo e facilidade de implantação quando comparada com quaisquer outras, deve ser considerada como uma forma de restringir a área a ser analisada em estudos de monitoramento agrícola e de modelagem do rendimento de grãos.

A partir da soma das áreas cultivadas com arroz irrigado em todas as safras de estudo (2000/01 até 2009/10), determinou-se a área potencial de cultivo do grão no Estado do RS (Figura 6). O mapeamento das áreas consideradas potenciais de serem utilizadas para o cultivo de arroz contabilizou 3.322.037 ha. Este valor é próximo à área passível de cultivo contabilizada em 4.000.000 descrita por Reis \& Saibro (2004).

A área média cultivada, estimada a partir das imagens MODIS (Tabela 1), em cada safra analisada correspondeu a aproximadamente 30\% da área potencial de cultivo. Assim, reforça-se a característica de adoção do sistema de pousio e rotação de culturas na região orizícola do RS. Em áreas de várzeas, essas práticas são consideradas como alternativa eficiente para o controle de plantas daninhas, promovendo também o aumento do rendimento de grãos do arroz irrigado cultivado na sequência do pousio ou rotação com culturas de sequeiro.

\section{Conclusão}

A metodologia proposta para determinar a distribuição espacial e quantificar as áreas cultivadas com arroz irrigado, baseada no comportamento espectro-temporal da cultura, é eficiente e pode ser usada tanto para complementar o atual sistema de previsão de safras, como para o monitoramento das áreas cultivadas no Rio Grande do Sul. Isto permite concluir que os dados gerados a partir desta metodologia podem introduzir objetividade às estatísticas agrícolas oficiais. Entretanto, convém salientar que, a possível inclusão de áreas cultivadas com outros cultivos de primaveraverão ainda devem ser melhores investigadas. 


\section{Agradecimentos}

Os autores deste trabalho agradecem as agências financiadoras Agência Brasileira de Inovação (FINEP) e a Coordenação de Aperfeiçoamento de Pessoal de Nível Superior (CAPES).

\section{Referências}

ARAÚJO, G. K. D. et al. Mapping of summer crops in the State of Paraná, Brazil, through the 10-day spot vegetation NDVI composites. Engenharia Agrícola, v. 31, p. 760-770, 2011.

ASSAD, E. D. et al. Sistema de previsão da safra de soja para o Brasil. PesquisaAgropecuáriaBrasileira, v.42, n.5, p.615-625, 2007.

BOSCHETTI, M. et al. Multi-year monitoring of rice crop phenology through time series analysis of MODIS images. InternationalJournalof Remote Sensing, London,v.30, n.18, p.4643-4662, 2009.

D'ARCO, E. O uso de geotecnologias para estimativa de área plantada de arroz irrigado no Estado do Rio Grande do Sul. 2007.206f. Tese (Doutorado) - Programa de Pós-graduação em Sensoriamento Remoto, Instituto Nacional de Pesquisas Espaciais, São José dos Campos, 2007.

D'ARCO, E.; RUDORFF, B. F. T.; RIZZI, R. Índice de vegetação para estimativa de área plantada com arroz irrigado. In: O SENSOR MODIS e suas aplicações ambientais no Brasil. São José dos Campos: Parêntese. 2007. Cap. 9, p. 123-131.

IBGE - Instituto Brasileiro de Geografia e Estatística. Levantamento Sistemático da Produção Agrícola. Disponível em: <http://www.sidra.ibge. gov.br/bda/agric>. Acesso em: 12 jun. 2013.

IBGE - Instituto Brasileiro de Geografia e Estatística.Pesquisas Agropecuárias. 2ed. Rio de Janeiro: IBGE, 2002. 92p (Séries relatórios metodológicos).

IRGA - Instituto Rio Grandense do Arroz Irrigado. Censo da Lavoura de arroz irrigado do Rio Grande do Sul - Safra 2004/05. IRGA, 2006. Disponível em:<http://www.irga.rs.gov.br/index. php? principal $=1 \&$ secao $=999 \&$ id $=124 \&$ menu$\mathrm{P}=124 \&$ key=3>. Acesso em: 5 abr. 2013.
IRGA - Instituto Rio Grandense do Arroz. Informações \& Mercado. Disponível em: $<$ http//www. irga.gov.br>. Acesso em: 04 fev. 2013.

KLERING, E. V. Avaliação do uso de imagens MODIS na modelagem agrometeorológicaespectral de rendimento de arroz irrigado no Rio Grande do Sul. 2007. 117f. Dissertação (Mestrado) - Programa de Pós-Graduação em Sensoriamento Remoto. Universidade Federal do Rio Grande do Sul, Porto Alegre, 2007.

LIU, W. T. H. Previsão de safra agrícola. In: APLICAÇÕES de Sensoriamento Remoto. Campo Grande: UNIDERP, 2006. p. 561-649.

MODIS - Moderate Resolution Imaging Spectroradiometer.Technical Specifications, 2003. Disponível em: <modis.gsfc.nasa.gov/about/specs. html> Acesso em: 26 mai. 2013.

MOREIRA, M. A. Fundamentos do Sensoriamento Remoto e Metodologias de Aplicação. $3^{\underline{a}}$ ed. Atual.Ampl.Viçosa: Editora UFV, 2005, 320p.

MOTOHKA, T. et al. Evaluation of optical satellite remote sensing for rice paddy phenology in monsoon Asia using a continuous in situ dataset. International Journal of Remote Sensing, London,v. 0, n.17, p.4343-4357, 2009.

PONZONI, F. J. Comportamento Espectral da Vegetação. In: MENEZES, P. R.; NETTO, J. S. M. Sensoriamento remoto: reflectância de alvos naturais. Brasília: UNIVERSIDADE DE BRASÍLIA, 2001. p.157-199.

REIS, J. C. L.; SAIBRO, J. C. de. Integração do arroz com pastagens cultivadas e pecuária. In: ARROZ irrigado no Sul do Brasil. Pelotas: Embrapa Clima Temperado; Brasília, DF: Embrapa Informação Tecnológica, 2004, cap. 24, p. 831-859.

RIZZI, R.; RUDORFF, B. F. T. Estimativa da área de soja no Rio Grande do Sul por meio de imagens Landsat. Revista Brasileira de Cartografia. v.57, n.3, p.226-234, 2005.

SAKAMOTO, T. et al. A crop phenology detection method using time-series MODIS data. Remote Sensing of Environment,New York, v. 96, n.1, p. 366-374, 2005. 
SANCHES, I. D.; EPIPHANIO,

J. C. N.; FORMAGGIO, A. R.

Culturasagrícolasemimagensmultitemporais do satélite Landsat. Agricultura de São Paulo, São

Paulo, v.52, n.1, p.83-96, 2005.

SOSBAI - Sociedade Sul-Brasileira de Arroz Irrigado. Arroz irrigado: Recomendações técnicas da pesquisa para o sul do Brasil. Porto Alegre: SOSBAI, 2010, 188.p

THIRUVENGADACHARI, S.;

SAKTHIVADIVEl,R.. Satellite Remote Sensing for Assessment of Irrigation System Performance: A Case Study in India.In: INTERNATIONAL IRRIGATION MANAGEMENT INSTITUTE, Research Report 9, 1997. Anais... Colombo: INTERNATIONAL IRRIGATION MANAGEMENT INSTITUTE, 1997.

WEBER, E. et al. Estimativa de área cultivada com arroz irrigado no Rio Grande do Sul na safra 2005/2006 através de imagens Landsat.. In: SIMPÓSIO BRASILEIRO DE SENSORIAMENTO REMOTO, 13., 2007, Florianópolis. Anais... São José dos Campos: INPE, 2007, p.465-472.

XIAO, X. et al. Mapping paddy rice agriculture in South and Southeast Asia using multitemporal MODIS images. Remote Sensing of Environment,New York, n.100, p. 95-113, 2006.

XIAO, X. et al. Mapping paddy rice agriculture in southern China using multi-temporal MODIS images.Remote Sensing of Environment,New York, v. 95, p. 480-492, 2005.

XIAO, X. et al. Observation of flooding and rice transplanting of paddy rice fields at the site to landscape scales in China using VEGETATION sensor data .International Journal of Remote Sensing,London, v. 23, n. 15, p. 3009-3022, 2002. 